\title{
Supersonic Aerodynamic Characteristics of Proposed Mars '07 Smart Lander Configurations
}

\author{
Kelly J. Murphy*, Thomas J. Horvath*十. Gary E. Erickson ${ }^{\ddagger}$ \\ NASA Langley Research Center, Hampton. VA 23681 \\ Joseph M. Green \\ Mississippi State University, Mississippi State, MS 39762
}

Supersonic aerodynamic data were obtained for proposed Mars '07 Smart Lander configurations in NASA langley Research Center's Unitary Plan Wind Tunnel. The primary objective of this test program was to assess the supersonic aerodynamic characteristics of the baseline Smart Lander configuration with and without fixed shelf/tab control surfaces. Data were obtained over a Mach number range of 2.3 to 4.5 , at a free stream Reynolds Number of 1 $x 10^{6}$ based on body diameter. All configurations were run at angles of attack from -5 to 20 degrees and angles of sideslip of -5 to 5 degrees. These results were complemented with computational fluid dynamic (CFD) predictions to enhance the understanding of experimentally observed aerodynamic trends. Inviscid and viscous full model CFD solutions compared well with experimental results for the baseline and 3 shelf/tab configurations. Over the range tested, Mach number effects were shown to be small on vehicle aerodynamic characteristics. Based on the results from 3 different shelf/tab configurations, a fixed control surface appears to be a feasible concept for meeting aerodynamic performance metrics necessary to satisfy mission requirements.

\section{Nomenclature}

$\mathrm{C}_{\mathrm{A}} \quad$ axial-force coefficient

$\mathrm{C}_{\mathrm{D}}$ drag-force coefficient

$\mathrm{C}_{\mathrm{L}} \quad$ lift-force coefficient

$\mathrm{C}_{\mathrm{L} \alpha} \quad$ lift-force curve slope

$\mathrm{C}_{1} \quad$ rolling-moment coefficien

$\mathrm{C}_{1 \beta} \quad$ rolling-moment beta derivalive, $\mathrm{dC} / \mathrm{d} \beta$

$\mathrm{C}_{\mathrm{m}} \quad$ pitching-moment coefficient

$\mathrm{C}_{\mathrm{m} \alpha}$ pitching-moment alpha derivative, $\mathrm{dC}_{\mathrm{m}} / \mathrm{d} \alpha$

$\mathrm{C}_{\mathrm{n}}$ yawing-moment coefficient

$C_{n \beta}$ yawing-moment beta deriv ative, $d C_{n} / d \beta$

$\mathrm{C}_{\mathrm{N}} \quad$ normal-force coefficient

$\mathrm{C}_{\mathrm{N} \alpha}$ normal-force alpha deriv ative, $\mathrm{dC}_{\mathrm{N}} / \mathrm{d} \alpha$

$\mathrm{C}_{\mathrm{Y}}$ side-force coefficient

$\mathbf{L}_{\mathrm{ref}}$ longitudinal reference length

$\mathrm{M}$ Mach number

$p_{\infty} \quad$ static pressure of free streim, psia

$\mathrm{pt}_{\mathrm{t}} \quad$ tunnel stagnation pressure. psia

$q_{\infty}$ free stream dynamic pressure, psia

$\mathrm{Re}_{\infty}$ free stream unit Reynolds number/ft

$S_{\text {ref }}$ reference area

$S_{\text {Ames }}$ "Ames" tab reference area

$\mathrm{S}_{\text {Canted }}$ "Canted" tab reference are: $\mathrm{t}$

$\mathrm{S}_{\text {Shelf }}$ "Shelf" reference area

$\mathrm{T}_{\infty} \quad$ static temperature of free stream, ${ }^{\circ} \mathrm{R}$

$\mathrm{T}_{\mathrm{t}} \quad$ tunnel stagnation temperiture, ${ }^{\circ} \mathrm{R}$

$\alpha \quad$ angle of attack, deg

$\beta \quad$ angle of sideslip, deg

*Aerospace Technologist, Aerothermodynamics Branch.

Aerodynamics, Aerothermodynamics and Acoustic Competency

¥ Aerospace Technologist. Research Facilities Branch.

Aerodynamics, Aerothermodynamic! and Acoustic Competency

Aerospace Engineering Cooperative I ducation Student.

Mississippi State University.

+ Member AIAA

\section{Introduction}

As part of NASA's on-going Mars Exploration Program, several planned missions include sample return requirements. These future missions will require a highly precise entry through the Martian atmosphere and a "smart" landing with the ability to detect and avoid hazards on the planet's surface. A key component to enabling these highly accurate trajectories and precise landings is reduction of uncertainties in the aerodynamic characteristics of the vehicle's aeroshell. The Mars '07 Smart Lander program was established to land a vehicle on the Martian surface with the dual goals of furthering basic scientific research on Mars as well demonstrating a host of "smart" technologies needed for a Mars Sample Return mission. Smart Lander technology goals include demonstration of a precision landing within a \pm 5 -kilometer footprint and a 100-meter site redesignation capability for hazard avoidance, enabling surface mobility of a rover to successfully navigate from the landing site to a pre-determined target location.'

Both low-L/D and mid-L/D aeroshell shapes were initially considered among the numerous '07

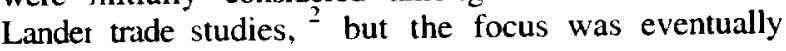
turned to a low-L/D shape with Pathfinder/Viking heritage. The Mars '07 Lander baseline aeroshell is a 4.05-meter diameter spherically blunted 70-degree cone with a biconic backshell (Fig. 1). The large cone halfangle is required to produce the necessary drag to decelerate the Lander's entry mass (approximately $\mathbf{2 3 0 0}$ $\mathrm{kg}$ ) at sufficiently high altitudes to permit parachute deployments in both the supersonic and subsonic flight regimes. To provide sufficient control authority and the necessary cross range capability, the configuration 